\title{
COMPORTAMENTO DO CONSUMIDOR DURANTE A PANDEMIA DA COVID-19
}

\author{
Mariana Peres Sant'Ana. Universidade São Judas Tadeu. USJT \\ Marianape.santana@gmail.com \\ Guilherme Coutinho Silva. Universidade São Judas Tadeu. USJT \\ Guilherme.coutinhosilva@hotmail.com \\ Natasha Guimarães Diogo. Universidade São Judas Tadeu. USJT \\ Natashagdiogo1999@gmail.com \\ Enio Tadashi Nose. Universidade São Judas Tadeu. USJT \\ noseenio@uol.com.br
}

\section{RESUMO}

O objetivo geral do presente trabalho é verificar como as mídias sociais foram importantes no processo de decisão de compra dos consumidores durante o isolamento social e a pandemia da COVID-19. Utilizando como metodologia principal a pesquisa bibliográfica, de caráter quantitativo. Pode-se verificar que a pandemia acelerou o processo no que se refere ao conhecimento do comportamento das pessoas ao consumir produtos e serviços. Muitos consumidores resistentes até então, compravam apenas através de lojas físicas, porém perceberam que precisam reinventar seus modelos de compras, efetuando-as também através de forma online.

Palavras-Chave: Comportamento do consumidor; Mídias Sociais; COVID-19

Data de recebimento: $23 / 06 / 2021$

Data do aceite de publicação: 03/08/2021

Data da publicação: 30/08/2021 


\title{
CONSUMER BEHAVIOR DURING THE COVID-19 PANDEMIC
}

\author{
Mariana Peres Sant'Ana. Universidade São Judas Tadeu. USJT \\ Marianape.santana@gmail.com \\ Guilherme Coutinho Silva. Universidade São Judas Tadeu. USJT \\ Guilherme.coutinhosilva@hotmail.com \\ Natasha Guimarães Diogo. Universidade São Judas Tadeu. USJT \\ Natashagdiogo1999@gmail.com \\ Enio Tadashi Nose. Universidade São Judas Tadeu. USJT \\ noseenio@uol.com.br
}

\begin{abstract}
The objective of this work is to verify how social media were important in the purchase decision process of consumers during social isolation and the COVID-19 pandemic. Using bibliographic research as the main methodology, with a quantitative character. It can be seen that the pandemic accelerated the process in terms of knowledge of people's behavior when consuming products and services. Many resistant consumers until then, bought only through physical stores, but realized that they need to reinvent their shopping models, making them also through online.
\end{abstract}

Key Word: Consumer Behavior, Social Media; COVID-19

\section{INTRODUÇÃO}

É de conhecimento geral que o mundo vem enfrentando uma grande adversidade, seguramente nunca vista no período contemporâneo. O novo Coronavírus compreende em uma gripe altamente viral que afeta diretamente o sistema respiratório humano, devido ao seu recente surgimento não há defesas.

O perigo desse novo vírus está na sua transmissão, é extremamente fácil contrair o vírus devido as suas propriedades, problemática que é somada com a restrita e insuficiente quantidade de informações comprovadas sobre o novo Coronavírus. Em busca de conter essa transmissão em curto prazo, os maiores governos do mundo, bem como a Organização Mundial de Saúde, passaram a incentivar o isolamento social e a quarentena voluntária. Como medida de incentivo a essa prática, os comércios locais precisaram ser fechados, assim como restaurantes, cinemas, casas noturnas, bares e todo e qualquer evento onde uma quantidade considerável de pessoas estivesse concentrada. 
Tal realidade causou um grande colapso no sistema econômico dos países, principalmente no caso do Brasil que ainda não havia se quer se recuperado da crise que o assola desde o ano de 2015 com questões de natureza política complexas envolvidas.

Por esse motivo, passou a ser necessário que as organizações desenvolvessem novas formas de fazer marketing, visando captar esse novo comportamento do consumidor. A consolidação da internet e dos meios tecnológicos abre caminho para um novo tipo de propaganda, aquele que - literalmente - se propaga em ambiente virtual.

Mas, o contexto da pandemia causou grandes alterações nesse meio e em todos os setores do mundo, mais precisamente no que se refere ao comércio online que vinha em grande crescimento e foi muito aquecido pelas indicações de isolamento social para conter a disseminação do vírus (Aveni, 2020).

Ainda segundo Aveni (2020), em apenas seis meses as vendas por via online tiveram um crescimento extraordinário, porém as recomendações de isolamento social e as restrições de abertura de shoppings e lojas não serão eternas. Sendo necessário que as organizações busquem formas de manter esse setor aquecido e viabilizar o crescimento constante das vendas online, acompanhando a digitalização processual pela qual o mundo vem passando.

Entender o comportamento do consumidor é algo que todas as instituições almejam alcançar. Tal conhecimento é importante para aquelas que pretendem obter, aumentar e/ou manter a satisfação de seus clientes, bem como maximizar os lucros da organização. Para isso, é necessário o acompanhamento das necessidades e desejos de seus potenciais clientes. O ponto de partida para conhecer e satisfazer as necessidades e desejos dos clientes, é tentar compreender o comportamento do consumidor e estudar como as pessoas, grupos e organizações selecionam, compram, usam e descartam produtos ou serviços (Kotler, 2000).

O objetivo geral do presente trabalho é verificar como as mídias sociais foram importantes no processo de decisão de compra dos consumidores durante o isolamento social e a pandemia da COVID-19.

\section{REFERENCIAL TEÓRICO}

\subsection{Comportamento do Consumidor}

O comportamento do consumidor pode ser definido segundo Rook (2007) como "as atividades diretamente envolvidas em obter, consumir e dispor de produtos e serviços, incluindo os processos decisórios que antecedem e sucedem estas ações". Com o mesmo pensamento, 
Sheth, Mittal e Newman (2001) definem o comportamento do consumidor como as atividades físicas e mentais realizadas por clientes de bens de consumo e industriais que resultam em decisões e ações, como comprar e utilizar produtos e serviços, bem como pagar por eles. Em síntese, as definições propostas de comportamento do consumidor incluem várias atividades e muitos papéis que as pessoas podem assumir.

O estudo do comportamento do consumidor é o estudo de como os indivíduos tomam decisões de gastar seus recursos disponíveis (tempo, dinheiro, esforço) em itens relacionados ao consumo (Schiffman e Kanuk, 2000). Tal estudo se desassocia do seu objeto de estudo, por isso alguns autores concebem comportamento do consumidor como estudo e não como atividade e/ou processo.

Por exemplo, Hawkins (2001) define o comportamento do consumidor como o estudo de pessoas, grupos ou organizações e os processos que utilizam para selecionar, obter, usar e dispor de produtos, serviços, ideias ou experiências para satisfazer necessidades e o impacto que estes processos têm no consumo e na sociedade. Em outras palavras, é o estudo das unidades compradoras e dos processos de trocas envolvidos na aquisição, no consumo e na disposição de mercadorias, serviços, experiências e ideias (Mowen e Minor, 2003).

Da mesma forma, Solomon (2011, p. 33) define o comportamento do consumidor como “o estudo dos processos envolvidos quando indivíduos ou grupos selecionam, compram, usam ou descartam produtos, serviços, ideias ou experiências para satisfazer necessidades e desejos". Essas últimas definições abordam o estudo do comportamento do consumidor como uma ferramenta para conhecer as necessidades e desejos de possíveis clientes e como eles se comportam quando estão inseridos no processo de compra.

Com base em tais definições, o comportamento do consumidor, para efeito desse estudo, refere-se ao processo mental e comportamental em que os consumidores percorrem antes, durante e depois de escolher ou não, consumir um produto ou serviço. Antes de abordar tal processo e suas características, convém analisar alguns fatores que o influenciam. Segundo Kotler e Armstrong (2015, p. 116) “o comportamento do consumidor também é influenciado por fatores sociais, como pequenos grupos, família, papéis sociais e status", que exercem um elevado grau de influência sobre as pessoas.

Churchill e Peter (2010, p. 160) conceituam grupos de referência como sendo "pessoas que influenciam os pensamentos, sentimentos e comportamentos dos consumidores". As pessoas buscam ser influenciadas por agentes que tenham algum conhecimento na área. Kotler 
e Keller (2012), em sua abordagem literária, explicam que os grupos são muito importantes para definir as normas de comportamento de um indivíduo.

Todas as pessoas, de uma ou outra maneira, participam de um grupo, entre eles a família, as organizações, clubes, igreja, escola e amigos. Para Kotler e Armstrong (2015, p. 116) "os grupos que exercem influência direta sobre uma pessoa e dos quais ela faz parte são chamados grupos de associação", já os grupos de referência funcionam como pontos de referência diretos ou indiretos e de comparação na formação do comportamento do consumidor. Ribeiro (2015, p. 81) afirma que "grupos de referência, atuam como elementos de comparação ou referência direta ou indireta no comportamento de uma pessoa", e que grupos de associação é o que tem relação direta com o indivíduo.

A família é o grupo de referência primária mais influente na decisão comportamental de consumo e constitui a mais importante organização de compra de produtos na sociedade do consumo (Kotler e Keller, 2012).

No decorrer de sua vida, o ser humano é enquadrado em vários grupos distintos, exercendo diversos papéis e posições sociais. O indivíduo adquire produtos que identifiquem facilmente seu papel e status no ambiente, o qual, consiste na atividade que ela deve desempenhar na sociedade, e carrega consigo um status que assegura que os indivíduos selecionam produtos que comunicam um papel ou status, seja ele real ou desejado, na sociedade (Kotler, 2006).

Fazendo e aprendendo os indivíduos tomam para si crenças e atitudes que são influenciadores em seu comportamento de compra. Uma crença é uma ideia descritiva que um indivíduo possui com relação a algo. As crenças podem apresentar embasamento em conhecimento, opinião ou fé. Elas podem ou não conter um aditivo emocional. Essas crenças constituem conceitos de marcas e produtos e as pessoas atuam de acordo com esses conceitos. É possível para a empresa lançar campanhas para corrigir crenças equivocadas que inibem a compra de produto ou serviço (Kotler, 2005).

Atitudes correspondem a predisposições aprendidas para responder a um objeto. Consumidores cultivam atitudes a uma variedade de objetos que teoricamente resumem a avaliação do consumidor sobre um produto, marca ou empresa e representam sentimentos positivos ou negativos em relação a eles, assim como suas tendências comportamentais (Belch, 2008).

A sociedade ao longo do tempo foi caracterizada por diversas mudanças em sua maneira de se comunicar, evoluindo de uma comunicação rudimentar até a troca de informações por 
meio de espaços digitais. Mas não foi apenas a forma de se comunicar que mudou, a maneira como as pessoas trabalham, compram e se relacionam, também sofreu fortes transformações. Isso fica cada vez mais evidente quando se observa a camada de pessoas com menor faixa etária. Essa camada mais jovem, que já nasce familiarizada com as novas tecnologias, é caracterizada por constituir-se de pessoas altamente informadas e capazes de se comunicar de forma que, há alguns anos, era totalmente impossível (Ferreira Filho e Nascimento e Sá, 2012).

\subsection{A Influência das Mídias Sociais no Comportamento do Consumidor}

A internet tem um papel importante nessa transformação, algumas de suas ferramentas auxiliaram na construção de um novo método de comunicação entre as pessoas. Entre essas ferramentas destacam-se as redes sociais. Atualmente, as redes sociais apresentam um número significativo de usuários ativos e estão cada vez mais disponíveis para as pessoas. Em um estudo produzido pela agência We Are Social em parceria com a plataforma de mídia Hootsuite, coletou-se dados de 22 milhões de usuários em 45 países. Foi constatado que dos 7,6 bilhões de pessoas no mundo 4 bilhões (53\%) têm acesso à internet, 3,1 bilhões (42\%) são usuários ativos de redes sociais e 2,9 bilhões (39\%) usam as redes sociais pelos seus dispositivos móveis, especialmente os smartphones (We are Social e Hootsuite, 2018).

As redes sociais são excelentes ferramentas que permitem maior comunicação entre pessoas em toda parte do mundo, de forma simples e rápida. De modo que hoje em dia, até mesmo pequenas empresas estão buscando interagir com seus clientes através dessas redes. Alguns estudos têm mostrado que existe uma relação entre as redes sociais e o comportamento do consumidor, principalmente na decisão de compra (Ferreira et al., 2017).

Os estudos que envolvem as variáveis redes sociais e o comportamento de compra do consumidor, realizados nos últimos cinco anos, focam essa temática em nichos específicos, como produtos gamers (Oliveira e Moreira Neto, 2016) e viagens aéreas (Brito e Freitas, 2019). Ou analisam grupos de comercio informal dentro de uma rede social específica (Sousa Júnior et al., 2018). Também procuram verificar se existe associação entre gênero e a compra de produtos indicados em redes sociais, e se há diferença na importância dada a indicações ou avaliações dispostas na rede social por gênero na amostra selecionada (Fonseca et al., 2015).

As redes sociais trouxeram grandes mudanças de comportamento para toda a humanidade, na forma de se relacionarem, na rapidez com que se trocam informações, influenciando pessoas e despertando nessas pessoas interesses que elas nem sabiam que os tinham. 
Para Frazão (2013), houve uma mudança na maneira como os indivíduos pesquisam o que elas precisam, e como as mesmas visualizam as novidades que estão em cada esquina e como conhecem a qualidade de cada produto antes de usá-los, as redes sociais são criadas por pessoas e são elas que determinam quando, onde e quando querem usar os ambientes e as plataformas sociais.

Segundo Adolpho (2010), a redes sociais são um meio de expressarmos nosso estilo de vida, por serem expressões humanas e descomprometidas, elas trazem entre si muito mais credibilidade. O espírito das mídias sociais vai além de conversarmos com nossos amigos ou da coleção de amigos que fazemos em cada uma dessas ferramentas, elas são uma parte de nossa identidade.

Redes sociais são redes de pessoas onde que elas estejam, a maneira como essas pessoas se relacionam é que determina se essa rede é presencial ou digital, são importantes opções para expandir os seus contatos e mantê-los sólidos, atualizados e sintonizados (Grando, 2012).

Um dos grandes objetivos das redes sociais é estimular a interatividade de pessoas, dar e buscar opiniões, com isso, o vendedor digital deve participar e contribuir para esse uso. É importante constatar que as pessoas também usam a internet para entretenimento, como, lazer, promoções, cupons de descontos, entre outras. As redes sociais permitem postar fotos e vídeos podendo inclusive comentar e compartilhar seus links, hotsites (Frazão, 2013).

É de suma importância para uma empresa ter um perfil social em uma rede social, é através dessa ferramenta que o empreendedor pode ficar a par da satisfação, desejos, problemas, resoluções e outros. Estar conectado o tempo todo é essencial para poder resolver todas as questões relacionadas ao cliente, para que assim ele não migre para a concorrência.

Segundo uma pesquisa realizada pela TracyLocke Brasil em associação com a Behup, cerca de $70 \%$ dos brasileiros alteraram o seu comportamento de consumo, passando a comprar mais pela internet, incluindo aquele público que nunca tinha realizado essa ação e dando preferência para comércios locais com produtos específicos e necessários a sobrevivência, como de alimentação (Globo, 2020).

O estudo contou com a participação de mil pessoas de todos os Estados do Brasil e foi realizado durante todo o mês de março, com o objetivo de identificar os impactos não apenas do vírus, mas do isolamento social no comportamento de compra das pessoas. Os resultados apontam que 66,2\% das pessoas passaram a realizar comprar de alimentação, higiene e demais mantimentos em mercados, padarias e farmácias do bairro, e $20 \%$ alegam terem alterado de forma extremamente radical seu comportamento de compra. 
Enquanto isso, o Sebrae é o responsável por divulgar a pesquisa realizada pelo Instituto Nielsen que aponta que o comportamento de consumo dos brasileiros durante a pandemia está mais voltado para produtos relacionados a saúde, alimentação, higiene, limpeza e internet, tendo em vista o isolamento social e a imposição muito comum de trabalhar e estudar de forma remota (Sebrae, 2020).

Os comércios de modo geral sofrem com as implicações da pandemia e precisam desenvolver novas formas de se conectar, abordar, captar e fidelizar clientes. Não apenas com objetivo de crescimento, mas principalmente como medida de segurança para a continuidade da vida útil do negócio.

\section{METODOLOGIA}

Para realização desse estudo utilizamos o método de pesquisa bibliográfica de caráter quantitativo para avaliar e compreender as opiniões e comportamentos dos respondentes, no qual obtivemos os dados por meio de um questionário de múltipla escolha através do Google Forms que foi disponibilizado pelos componentes do grupo para as pessoas.

A pesquisa bibliográfica é baseada no levantamento de referências teóricas já analisadas e publicadas através de escritos e eletrônicos, como livros, artigos científicos e páginas de web sites (Fonseca, 2002). A pesquisa qualitativa não se preocupa com representatividade numérica e sim com o aprofundamento da compreensão de um grupo social ou de uma organização (Gerhardt e Silveira, 2009).

Foi elaborado um questionário de aplicação com 24 perguntas, sua aplicação durou 5 dias e teve divulgação através do WhatsApp, Facebook e LinkedIn. Obteve-se 330 respostas válidas do formulário, mas houve a necessidade de descartar 16 respostas que representam $4,8 \%$ do total, pois esses respondentes nunca haviam feito compras pela internet.

Aplicou-se um questionário que englobava as variáveis que influenciavam o processo de compra online destacados por Philip Kotler (2005) e Gary Armstrong (2015) no referencial teórico do presente trabalho.

Diante da aplicação do questionário os dados foram processados através do Excel para geração de gráficos, visando atingir os objetivos relevantes de elaborar uma análise sobre o comportamento do consumidor durante a pandemia da COVID-19, onde se verificam as necessidades, confiabilidade, dificuldades e índice de se consumir no meio online. 


\section{COMPORTAMENTO DO CONSUMIDOR DURANTE A PANDEMIA DA COVID-19}

\section{ANÁLISE DE RESULTADOS}

De acordo com Waengertner (2018), o dinamismo do mercado não se pode mudar em razão de se afirmar que a velocidade das transformações vem aumentando nos últimos tempos. Dessa forma, o que era certeza pode se transformar rapidamente em dúvida com os novos costumes de consumo e tecnologias. A pandemia do novo coronavírus mostrou que as empresas precisam inovar para atender ao consumidor, os quais apresentam novas necessidades, valores e hábitos de consumo, caso contrário as mesmas serão extintas.

Assim sendo, a amostra totalizou 314 pessoas, no qual a maioria dos respondentes foram mulheres $(71 \%)$ e a faixa etária total da amostra variou de acordo com o Gráfico 1.

Gráfico 1 - Qual sua faixa etária

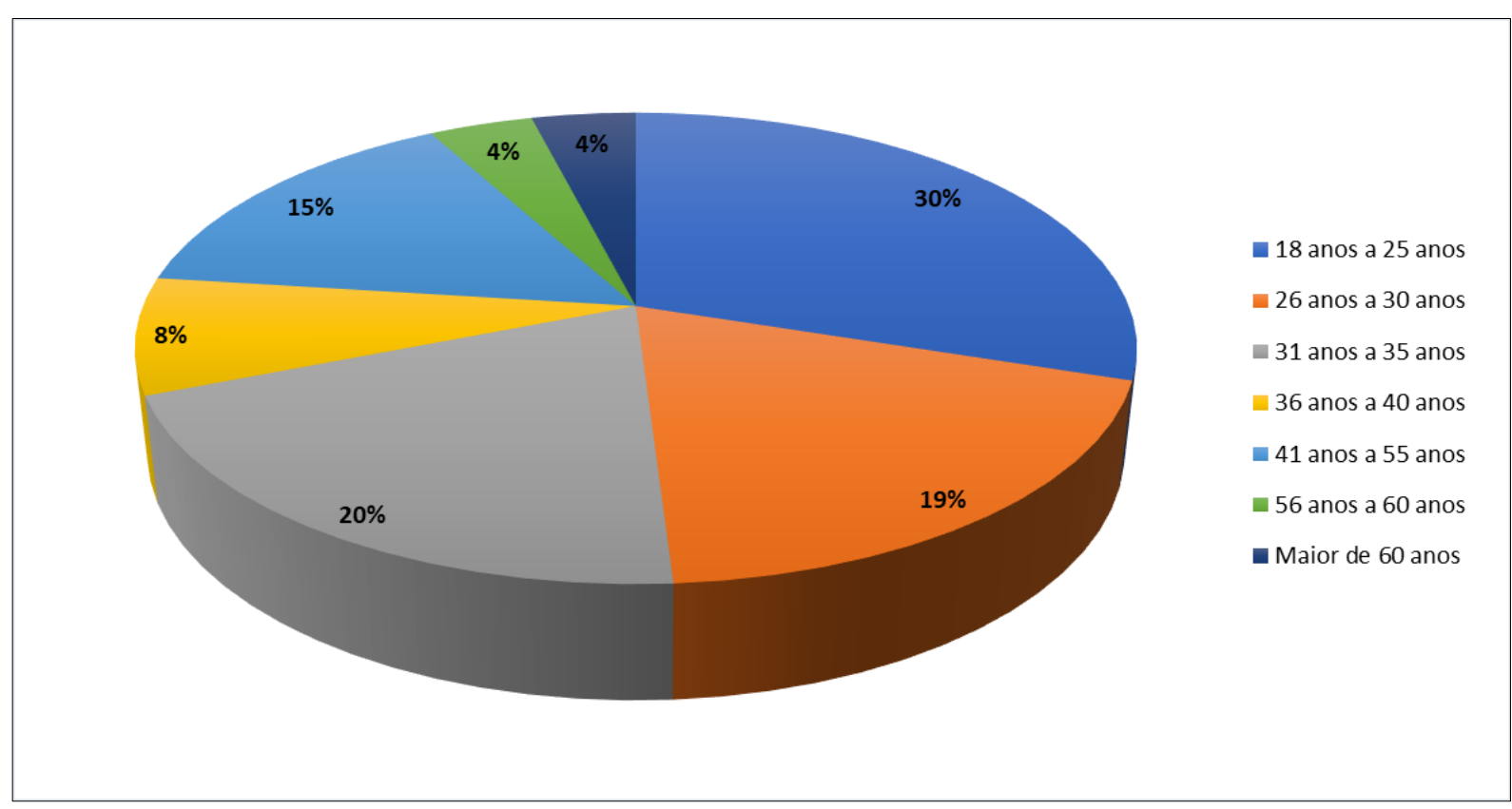

Fonte: Elaborado pelos autores.

Em relação à quantidade majoritária de mulheres que responderam a pesquisa, é importante destacar que as mulheres são responsáveis pelas compras em 96\% dos lares de acordo com o estudo realizado pela Nielsen (2019 apud ALMEIDA et al, 2020), empresa global de mensuração e análise de dados, em relação ao comportamento dos consumidores brasileiros. Além disso, as mulheres são mais propensas a responder questionários de pesquisas como esta.

Os dados indicam que $70 \%$ dos entrevistados estão trabalhando atualmente e $65 \%$ dos respondentes possuem renda familiar de até $\mathrm{R} \$ 5.225,00$. 
De forma geral os produtos mais comprados nos últimos 8 meses com $31 \%$ de respostas consistem em itens de primeira necessidade (alimento, produto de higiene pessoal, produto de limpeza, medicamentos), seguido de cosméticos (beleza e perfumaria) com 15\% de respostas e produtos para animais de estimação com 14\% de respostas. Os itens de moda e acessórios obtiveram $11 \%$ de respostas, os itens eletroeletrônicos e/ou eletrodomésticos e cursos online obtiveram $7 \%$ de respostas, os livros e revistas obtiveram $6 \%$ de respostas, móveis $5 \%$ de respostas e outros itens obtiveram $4 \%$ de respostas.

Os dados indicam que $76 \%$ dos indivíduos já tinham o hábito de realizar compras através da internet antes da pandemia. $\mathrm{O}$ advento do coronavírus e o consequente fechamento das lojas influenciaram as compras online, pois $95 \%$ das pessoas indicaram que elas ou alguém da mesma residência fizeram compras através da internet no período de isolamento social, representando um aumento de $19 \%$.

Dessa forma, a pesquisa comprova a importância para as empresas e marcas comandarem as técnicas de vendas pela internet.

As empresas de menor porte, que ainda não estão atentando para isso, precisam começar a marcar sua presença na internet de alguma forma, seja por meio de um site institucional ou blog, pela participação em redes sociais, ou por anúncios como banners em grandes portais, links patrocinados nos sites de busca, entre outras opções ou ainda iniciar uma operação e-commerce para realizar transações comerciais pela web. E a razão para isso é muito simples: porque os clientes convencionais e, principalmente os potenciais estão lá, bem como as empresas concorrentes (Turchi, 2017, p. 6).

Ainda em relação em efetuar compras online, 50\% dos indivíduos respondentes indicam que já compraram pela internet produtos e/ou serviços, $44 \%$ responderam que frequentemente efetuam compras através da internet e $6 \%$ responderam que preferem que outra pessoa que tenha o hábito de comprar pela internet realize a compra para elas.

O Gráfico 2 apresenta o consumo médio em compras online nos últimos 8 meses. 
Gráfico 2 - Quanto você gastou em média nos últimos 8 meses em compras online?

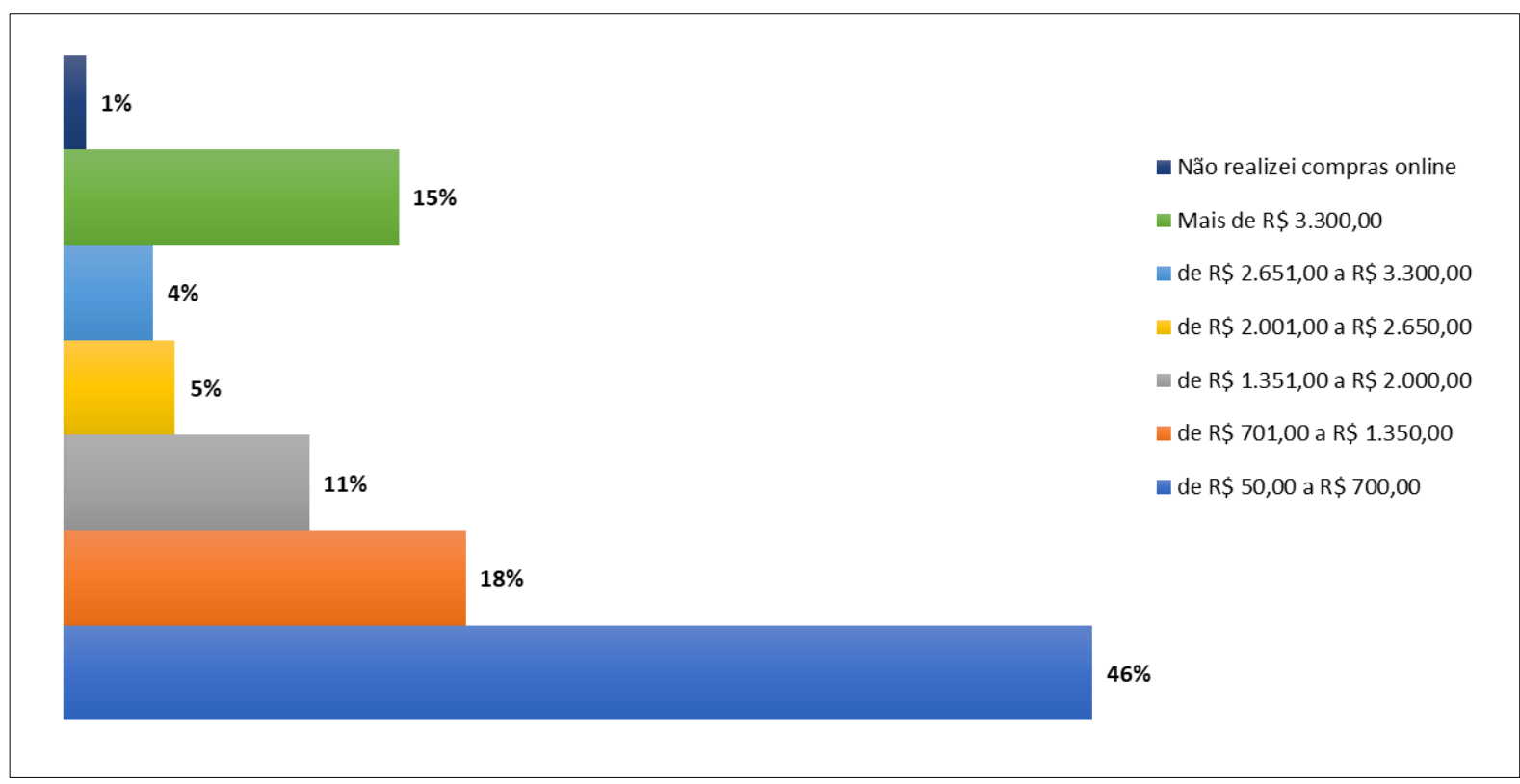

Fonte: Elaborado pelos Autores.

Verifica-se que a maioria dos indivíduos (46\%) consumiram produtos no valor relativamente baixo, quando comparado com os demais. Vale ressaltar que $15 \%$ dos indivíduos efetuaram compras acima de $\mathrm{R} \$ 3.300,00$, um valor substancialmente alto, o que não era esperado em tempos de pandemia.

Em relação à forma de pagamento, $50 \%$ dos entrevistados indicam que, ao realizar suas compras em lojas online ou em lojas físicas, efetuam o pagamento de forma à vista, $45 \%$ efetuam o pagamento de forma parcelada e 5\% efetuam o pagamento através de crédito disponível no PayPal, PicPay e Cash back.

Os dados indicam que a maioria das pessoas entrevistadas acreditam que ambas as formas de compra (online ou através da loja física) são vantajosas, $28 \%$ das pessoas preferem comprar de forma online e $21 \%$ através da loja física.

Com o advento da tecnologia, da internet, da informação e a transformação digital vários autores (Turchi, 2017; Mendes e Bueno, 2018; Vaz, 2011) expõem a importância de se incorporar estratégias de atendimento e venda online, no entanto, empreendedores ainda relutam em reinventar seus negócios nessa dimensão (Almeida et al., 2020).

Nesse sentido, fazer uso das estratégias de omnichannel pode ser uma alternativa. De acordo com Almeida et al. (2020, p. 4):

Carvalho e Campomar (2014) propõem essa abordagem relacionada à ideia de que os clientes podem acessar as informações online mesmo estando dentro de uma loja física, tendo contato com 
promoções, preço e vantagens. O omnichannel visa integrar os canais disponíveis - físicos e virtuais -, a fim de conquistar e se adaptar ao consumidor que exige respostas rápidas e mais opções no varejo.

O Gráfico 3 mostra os aspectos que podem induzir o consumidor a não efetuar a compra através das lojas online.

Gráfico 3 - O que pode te impedir em comprar através das lojas online?

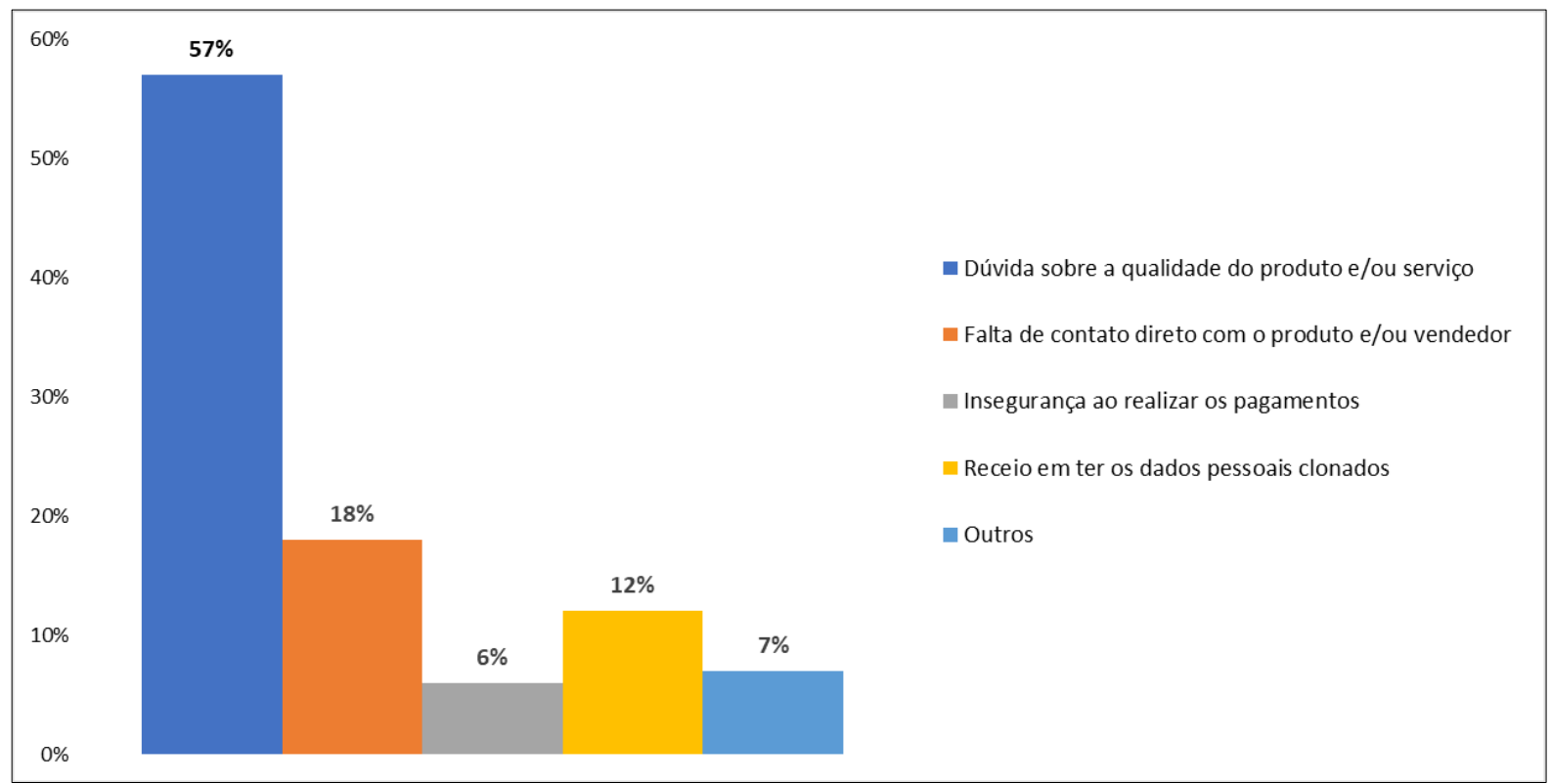

Fonte: Elaborado pelos Autores.

O principal motivo apresentado pelos consumidores é a dúvida sobre a qualidade do produto e/ou serviço (57\%). Além disso, a falta de contato direto com o produto e/ou vendedor $(18 \%)$ e o receio em ter os dados clonados (12\%) também recebem uma porcentagem significativa, $7 \%$ dos consumidores apresentaram outros motivos e 6\% apresentaram insegurança ao realizar os pagamentos.

O Gráfico 4 mostra os aspectos fundamentais em relação à segurança de fazer compras online.

Entre as informações coletadas verifica-se que o principal receio do consumidor consiste em saber se a loja é confiável, com 39\% dos consumidores respondendo que o aspecto mais seguro é conhecer a loja online e $23 \%$ dos consumidores informando que a opinião de outro consumidor sobre a loja gera mais segurança, representando 62\%. O segundo aspecto fundamental, que dá segurança aos consumidores para realizar a compra online é a qualidade do site e das informações de conteúdo, com $16 \%$. 
Gráfico 4 - Qual aspecto te dá mais segurança para realizar compras online?

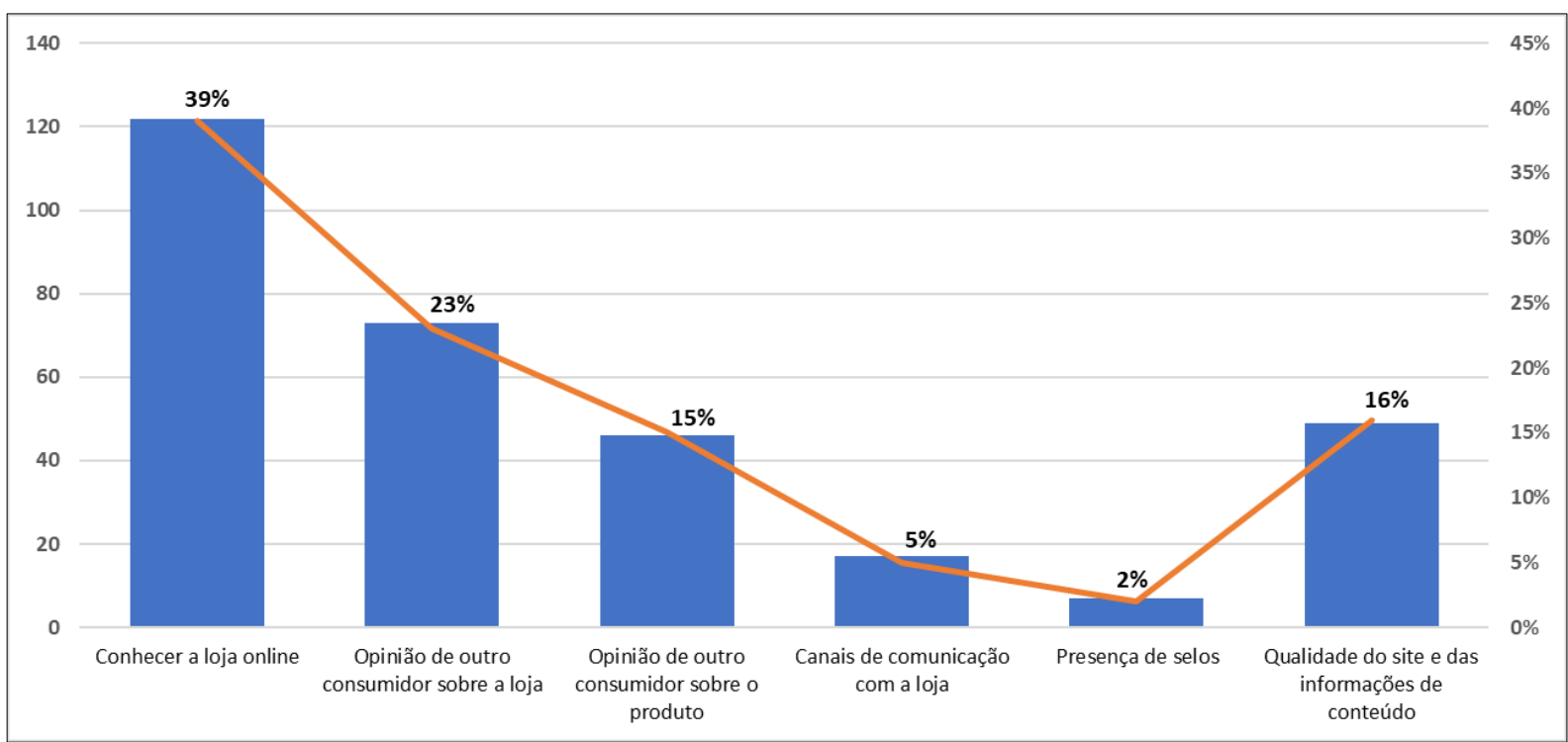

Fonte: Elaborado pelos Autores (2020).

Nesse sentido, os consumidores apresentaram que o canal mais importante para conhecer a reputação da loja online e tomar a decisão de compra é através do reclame aqui (24\%), seguido da opinião de amigos e consumidores (22\%), redes sociais (20\%), sites de pesquisa (16\%), site da loja (14\%) e publicidade (4\%).

"É preciso compreender que o consumidor não quer ver apenas venda explícita de produtos, é preciso se comunicar, gerando conteúdo que agregue valor em sua vida, que contribua com algo" (Almeida et al., 2020, p. 4).

"Seu conteúdo precisa agregar valor. A ideia de ter um conteúdo especialista é entregar informações úteis para quem precisa delas" (Rez, 2016 apud Almeida et al., 2020, p. 5). Segundo Almeida et al. (2020), se o indivíduo segue as redes sociais e sites, e não encontra conteúdo útil em relação ao que a empresa vende, não se gera valor e a reputação da empresa pode ser negativa. Sendo assim, nesse momento de pandemia é necessário planejar e/ou replanejar as estratégias de comunicação e, dessa forma, a venda será uma consequência futura de uma imagem positiva construída nesse cenário.

Apesar do receio por parte de vários consumidores, grande parte das respostas $(55 \%)$ apresentou que o motivo que o levou a efetuar a compra através da internet foi devido ao produto se apresentar mais acessível em relação ao preço. Entre os outros motivos estão: lojas fechadas devido ao isolamento social (32\%), influência da publicidade nos meios de 
comunicação digital através das mídias sociais $(10 \%)$ e pagamentos digitais que permite receber o dinheiro de volta (3\%).

Os dados indicam que $74 \%$ dos consumidores apresentam mais segurança em realizar compras nas lojas online em empresas que também possui lojas físicas. Além disso, $74 \%$ das pessoas indicam que passaram a confiar nos meios digitais para efetuar as compras, porém $26 \%$ das pessoas ainda preferem a opção de realizar as compras através de lojas físicas.

Por fim, a pesquisa indica que $92 \%$ dos entrevistados pretendem continuar comprando através dos meios digitais após a pandemia.

\section{CONCLUSÃO}

Este estudo verificou como as mídias sociais foram importantes no processo de decisão de compra dos consumidores durante o isolamento social e a pandemia da COVID-19.

Em razão ao cenário atual devido ao isolamento social antes e durante a pandemia da COVID-19, este estudo compreende a importância do marketing digital e as mídias sociais para a comunicação das empresas com os seus consumidores.

A pandemia do coronavírus acelerou o processo no que se refere ao conhecimento do comportamento das pessoas ao consumir produtos e serviços. Muitos consumidores compravam apenas através de lojas físicas, porém com o isolamento social perceberam que precisam reinventar seus hábitos de consumo saindo do modo tradicional para o modo online, todavia as empresas também devem se atentar às novas demandas, em especial ao que se refere ao mundo digital de acordo com as necessidades do consumidor.

Constata-se uma tendência ao consumo híbrido, ou seja, efetuar as compras não somente nas lojas físicas, mas também por meio de aplicativos, sites e mídias sociais, determinando que o mundo offline (loja/venda física) está se integrando ao mundo online (loja/venda digital), o que não significa ter que se transformar em uma empresa unicamente digital, mas sim ter uma maior presença online.

A principal dificuldade foi a adaptação do estudo face ao contexto atual causado pela doença do novo coronavírus onde algumas pessoas entrevistadas nunca realizaram compras através da internet, por consequência elas tiveram que ser removidas do estudo. Recomenda-se um estudo mais abrangente verificando as maiores dificuldades e quais motivos impactam em realizar ou não compras online, procedendo com a amostragem de ambas as formas, pessoal e digital. 


\section{REFERÊNCIAS}

Adolpho, C. (2010) Os 8Ps do marketing digital. São Paulo: Novatec Editora.

Almeida, M. R. C. de (2020) Comportamento de consumo em meio a pandemia da covid-19. In: XXV Jornada de Pesquisa. Ijuí. Anais. Ijuí. 1-8.

Aveni, A. (2020). Estratégias pelo trabalho no futuro devidos a pandemia COVID-19. Revista Processus de Políticas Públicas e Desenvolvimento Social, 2(3), 04-14.

Belch, G. E. (2008) Advertising and promotion: An Integrated marketing communication. Seattle, EUA. McGraw-Hill/Irwin; 8th ed.

Brito, F. W. C., \& Freitas, A. A. F. de (2019) Em busca de "likes": A influência das mídias sociais no comportamento do consumidor no consumo de viagens. Pasos. Revista de Turismo y Patrimonio Cultural, 17, 113-128.

Churchill Junior, G. A., \& Peter, J. P. (2010) Marketing: criando valor para os clientes. São Paulo: Saraiva.

Ferreira Filho, E. P., Nascimento, M. F. do, \& Sá, R. J. de (2012 Redes sociais digitais: uma nova configuração no estilo de vida da contemporaneidade. In: Simpósio de excelência em gestão e tecnologia, Rio de Janeiro. Anais: AEDB, 1-15.

Ferreira, A. C., Fagundes, A. F. A., Camargo, M. C. S., \& Oliveira, T. C. (2017) A pesquisa sobre redes sociais e comportamento do consumidor no Brasil. Revista Gestão \& Tecnologia, 17(2), 186-213.

Fonseca, F. A. da, Pelegrino, M. T., Imano, P. H., \& Oliveira, M. G. de (2015) Influência das redes sociais na compra. Memorial Tcc Caderno da Graduação, 1(1), 183-200.

Fonseca, J. J. S. (2002). Metodologia da pesquisa científica. Fortaleza: UEC.

Frazão, C. \& Kepler, J. (2013). O vendedor na era digital. São Paulo: Editora Gente.

Grando, N. (2012) Empreendedorismo Inovador: como criar startups de tecnologia no Brasil. São Paulo: Évora.

Gerhardt, T. E., \& Silveira, D. T. (2009). Métodos de pesquisa. Porto Alegre: Editora da UFRGS.

Globo (2020). Coronavírus: pandemia já mudou os hábitos de compra de $70 \%$ dos brasileiros, segundo pesquisa. <https://epocanegocios.globo.com//Brasil/ noticia/2020/04/coronavirus-pandemia-ja-mudou-os-habitos-de-compra-de-70-dosbrasileiros-segundo-pesquisa.html> Acesso em: 11 out.

Hawkins, D. I., Best, R. J., \& Coney, K. A. (2001). Consumer behavior: Building marketing strategy. Boston: Irwin/McGraw Hill. APA 6th ed.

Kotler, P., \& Keller K. (2012). Administração de Marketing. São Paulo: 14ª ed. Pearson Education do Brasil. 
Kotler, P. \& Armstrong, G. (2015). Princípios de Marketing. 12 ed. São Paulo: Pearson Prentice Hall.

Miniard, P. W., LI, F., \& Barone, M. J. (2000). The facilitating influence of consumer knowledge on the effectiveness of daily value reference information. Journal of the Academy of Marketing Science, 28(3), 425-436.

Mendes, R., \& Bueno, R. C. (2018). Mude ou morra: Tudo que você precisa saber para fazer crescer seu negócio e sua carreira na nova economia. São Paulo: Planeta do Brasil.

Mowen, J. C., \& Minor, M. S. (2003). Comportamento do consumidor. $1^{\text {a }}$ ed. Tradução Vera Jordan São Paulo: Prentice Hall.

Oliveira, I. C. de, \& Moreira Neto, A. L. da C. (2016). Comportamento do consumidor: a influência das mídias sociais na decisão de compra de produtos gamers. Revista de PósGraduação Faculdade Cidade Verde, 1(2), 30-52.

Ribeiro, L. (2015). Marketing social e comportamento do consumidor. Säo Paulo: Pearson Education do Brasil.

Rook, D. W. (2007). Dimensão ritual do comportamento de consumo. Revista de Administração de Empresas, 47(1), 81-98.

Schiffman, L. G., \& Kanuk, L. L. (2000). Comportamento do consumidor. Rio de Janeiro: LTC.

Sebrae (2020). Estudo mostra o novo comportamento do consumidor diante da pandemia. Disponível em: <https://www.sebrae.com.br/ sites/PortalSebrae/artigos/estudo-mostranovo-comportamento-do-consumidor-diante-da pandemia,9388ad41eab21710VgnVCM1000004c00210aRCRD> Acesso em: 11 out.

Sheth, J. N., Mittal, B., \& Newman, B. I. (2001). Comportamento do cliente: indo além do comportamento do consumidor. São Paulo: Atlas.

Solomon, M. R. (2011). O comportamento do consumidor: comprando, possuindo e sendo. 9. ed. Porto Alegre: Bookman.

Sousa Júnior, J. H. de, Silva, E. R. A. da, \& Melo, F. V. S. (2018). "Compro, vendo e troco": o consumo em grupos de comércio informal nas redes sociais virtuais. Desenvolve Revista de Gestão do Unilasalle, 7(3), 75-86.

Turchi, S. R. (2017). Estratégias de marketing digital e e-commerce. São Paulo: Atlas.

Vaz, C. A. (2011). Os 8 ps do marketing digital: o seu guia estratégico de marketing digital. São Paulo: Novatec Editora.

Waengertner, P. (2018). A estratégia da inovação radical: como qualquer empresa pode crescer e lucrar aplicando os princípios das organizações de ponta do Vale do Silício. São Paulo: Editora Gente.

We are Social, \& Hootsuite (2018). Digital in 2018. Lenders. 